\title{
O punctum da imagem
}

Ana Bartolo

PUC-RJ

\section{Resumo}

$\mathrm{O}$ artigo se desenvolve a partir dos termos com que Barthes, no livro A Câmara Clara, reverbera uma experiência temporal acionada pela imagem, no caso, pela fotografia, que se constitui critica e imageticamente na escrita. O historiador da arte francês André Rouillé, ao criticar a noção do "isso-foi", elaborada por Barthes no livro em questão, destaca um outro ponto de interesse central, qual seja, a rara beleza de uma narrativa sobre a recepção de uma imagem fotográfica. Assim, em nossa abordagem, tomamos esta observação como referência para seguir uma trilha conduzida pela noção de punctum, concebida por Barthes como um operador de temporalidades na imagem.

Palavras-chave: Roland Barthes; punctum; “isso-foi”; imagem; tempo.

\begin{abstract}
This article is based on the terms that in Barthes' book Camera Lucida reverberate a temporal experience triggered by images, in this case through photography, which forms a critical and visual part of writing. The French art historian André Rouillé, when criticizing the notion of "that-has-been", developed by Barthes in the book in question, highlights another central point of interest: the rare beauty of a narrative on the reception of a photographic image. Therefore, in our approach, we use this observation as a reference in order to follow a path laid out by the notion of punctum, conceived by Barthes as an operator of temporality within the image.
\end{abstract}

Keywords: Roland Barthes; punctum; "what was"; image; time. 
1. DIDI-HUBERMAN, Georges. O que vemos, o que nos olha, 2010, p.184.

2. A Câmara Clara foi o último livro escrito por Barthes antes de sua morte. Escrito em 1979, foi publicado em 1980.

3. ROUILLÉ, André. $A$

Fotografia - entre documento e arte contemporânea, 2009, p.217.

\section{Cf. DIDI-HUBERMAN,} Georges. O que vemos, o que nos olha, 2010.

5. BARTHES, Roland. A Câmara Clara: nota sobre a fotografia, 1984, p.12.

6. Ibidem, p.18.

7. Ibidem, p.17.
Como encontrar, como produzir com palavras a conflagração que, na imagem, nos olha?"

Georges Didi-Huberman

Roland Barthes, como ele mesmo afirmou, escreveu seu último livro, A Câmara Clara (1980), "tomado de um desejo ontológico" de compreender a essência da fotografia. O livro registra, em 48 pequenos capítulos, o processo dessa busca. Assim sendo, Barthes empreende na linguagem uma investigação sobre a natureza da fotografia utilizando-se de uma metodologia que se afigura como um caminho que só se faz ao andar. A Câmara Clara é um livro polêmico no que diz respeito à sua reflexão sobre a fotografia, mas, ainda assim, é uma obra que se mantém referencial no campo da fotografia, incontornável mesmo em uma reflexão que dela se afaste.

O historiador da fotografia André Rouillé, em sua obra A fotografia: entre documento e arte contemporânea, é um dos críticos das formulações de Barthes sobre a fotografia, embora ressalte um ponto de interesse que o texto produz: "o de oferecer uma descrição, de rara riqueza, da recepção de uma imagem fotográfica" ${ }^{3}$. No presente artigo, tomamos esta observação de Rouillé como referência para nossa abordagem do livro $A$ Câmara Clara. Qual seja, destacar no texto de Barthes essa experiência temporal acionada pela imagem, no caso, pela fotografia, e que se constitui critica e imageticamente na escrita. O que pretendemos assim é destacar a "língua" em que Barthes expõe aquilo que numa imagem o olha".

Barthes inicia A Câmara Clara comentando o espanto que sentiu ao ver, certa vez, uma fotografia do irmão de Napoleão. Segundo ele, o que o tocava na imagem era constatar que aqueles olhos tinham visto o Imperador. Ele relata que a sua incapacidade em expressar aquele espanto e a solidão de tentar compartilhar essa impressão o colocaram em condições de escrita, já que desejava saber, a todo custo, a "verdade" da fotografia, "o que ela era em si" 5 .

Ao iniciar o percurso, diante da dificuldade em selecionar um corpus fotográfico que o orientasse na busca, Barthes se sente "cientificamente sozinho e desarmado" ". Para ele, os livros que tratavam do assunto eram técnicos demais, olhando a fotografia de muito perto, ou determinados por uma perspectiva histórica e sociológica, ou seja, distantes do significante fotográfico. Diz ele: "eu constatava com desagrado que nenhum me falava com justeza das fotos que me interessavam, as que me dão prazer ou emoção"”:

Conclui então que essa desordem e esse dilema, evidenciados pela vontade de escrever sobre a Fotografia, refletiam uma espécie de desconforto que sempre me fora conhecido: 
o de ser um sujeito jogado entre duas linguagens, uma expressiva, outra crítica; e dentro desta última, entre vários discursos, os da sociologia, da semiologia e da psicanálise - mas que, pela insatisfação em que por fim me encontrava em relação tanto a uns quanto a outros, eu dava testemunho da única coisa segura que existia em mim (por mais ingênua que fosse): a resistência apaixonada a qualquer sistema redutor. ${ }^{8}$

Sendo assim, Barthes seleciona um conjunto de fotos que o afetam como os corpos singulares de uma constelação, para empreender uma tentativa de aproximação da verdade da fotografia: "nada a ver com um corpus: somente alguns corpos".

Ao se definir como um sujeito "jogado entre duas linguagens, uma expressiva, outra crítica”, Barthes expressa a importância de conjugar forma e conteúdo na elaboração do pensamento. No livro $A$ ula ${ }^{10}$, ele defende a necessidade de uma linguagem que se realize para além da "autoridade da asserção, do gregarismo da repetição"11 e convoca a língua da literatura para a produção do saber. O discurso do saber assim concebido é "ensaiado" no magnetismo da enunciação e não na autoridade de um enunciado. Para Barthes, não há sentido em uma "partilha das funções": um discurso das ciências e um discurso literário. Sendo assim, para ele, o texto é sempre "escritura", termo que utiliza para designar essa escrita elaborada na dinâmica de um registro crítico e expressivo.

Em A Câmara Clara, o pensamento de Barthes se produz em um ritmo intermitente de recomeços, em um "perambular de foto em foto". Este movimento do pensamento nos remete ao filósofo alemão Walter Benjamin, que, como Barthes, considerava que a produção do saber precisa considerar a sua elaboração no âmbito da linguagem. No conhecido prefácio de sua obra Origem do Drama Barroco Alemão, Benjamin elabora uma metodologia para lidar com aquilo que designa como "O ser indefinível da verdade" 12 . Neste prefácio, considera que o pensamento filosófico é constituído na escrita, no trabalho na espessura das palavras. Assim, para ele, a aproximação ao reino das idéias se traduziria na forma de um mosaico, cujo procedimento formal se dá na articulação de diferentes partes e não na apreensão de um todo que pudesse ser capturado em sua solidez de objeto:

Incansável, o pensamento começa sempre de novo, e volta sempre, minuciosamente, às próprias coisas. Esse fôlego infatigável é a mais autêntica forma de ser da contemplação. Pois ao considerar um mesmo objeto nos vários estratos de sua significação, ela recebe ao mesmo tempo um estímulo para o recomeço perpétuo e uma justificação para a intermitência do seu ritmo. Ela não teme, nessas interrupções, perder sua energia, assim como o mosaico, na
8. Ibidem, p.19.

9. Ibidem, p.19.

10. Transcrição da aula inaugural pronunciada por Barthes quando assumiu a cadeira de Semiologia Literária no Collège de France em 7 de janeiro de 1977.

11. BARTHES, Roland. Aula, 1996, p.14.

\section{BENJAMIN, Walter.}

"Questões introdutórias de crítica do conhecimento", 1984, p.50. 
É neste mesmo texto que Benjamin tematiza a relação entre as ideias e as constelações, ou seja, a necessidade de um conceito, entendido como forma de apresentação das ideias, de se orientar por uma diversidade de fenômenos, contornando diferentes singularidades, como as estrelas que formam uma constelação. Assim, aludimos brevemente a este método benjaminiano e à sua metáfora da constelação para dialogar com o procedimento investigativo de Barthes sobre seu objeto, no caso, a Fotografia com "f" maiúsculo, como ele coloca no livro em questão. Ao selecionar os "corpos" de sua constelação, Barthes pretendia que esta configuração o ajudasse a vislumbrar a verdade da Fotografia. Nesses percursos, cada imagem escolhida é um ponto de onde se olha o objeto, uma constelação que ganha forma nas relações entre seus elementos. Duplo registro, em que um conjunto de "pontos" (con-stelação) precisa transpor para a linguagem as condições necessárias para a sua constituição.

As fotos escolhidas por Barthes para guiá-lo em sua "aventura", palavra que escolhe para nomear a atração que essas imagens nele produzem, o levam a identificar dois tipos de motivação no contato com as imagens: o studium e o punctum.

14. "Eu não via, em francês, palavra que exprimisse simplesmente essa espécie de interesse humano; mas em latim, acho que essa palavra existe: é o studium". BARTHES, Roland. A Câmara Clara: nota sobre a fotografia, 1984, p.45.

15. Ibidem, p.45.

16. "Em latim existe uma palavra para designar essa ferida, essa picada, essa marca feita por um instrumento pontudo [...] Pois punctum é também picada, pequeno buraco, pequena mancha, pequeno corte - e também lance de dados". Ibidem, p.45

17. Ibidem, p.77.

18. BARTHES, Roland. $O$ Império dos Signos, 2007, p. 5.

19. Idem. A Câmara Clara: nota sobre a fotografia, 1984, p. 80. O studium $^{14}$ se caracteriza como um interesse mais geral (em algumas de suas palavras: "polido", "indolente", "amoroso", "gesto virtuoso") efetivado na abordagem da fotografia pelo viés mais amplo da cultura. É o envolvimento que se produz em um estudo que pretende codificar, classificar, interpretar uma imagem: "espécie de investimento geral, ardoroso, é verdade, mas sem acuidade particular" ${ }^{\prime 15}$. Esse interesse pelo saber não é desvalorizado por Barthes, ao contrário, já que é nesse registro que grande parte do conhecimento é produzido, inclusive o dele, sendo intelectual e professor. Já o punctum ${ }^{16}$ é designado por Barthes como um detalhe na fotografia que a consciência não pode nomear mas que, no entanto, orienta toda a leitura da imagem:

Um detalhe conquista toda a minha leitura; trata-se de uma mutação viva de meu interesse, de uma fulguração. Pela marca de alguma coisa, a foto não é mais qualquer. Esse alguma coisa deu um estalo, provocou em mim um pequeno abalo, um satori, a passagem de um vazio. ${ }^{17}$

Em O Império dos Signos (1970), livro em que se aproxima da cultura japonesa em busca de uma "fissura do simbólico", Barthes já alude a essa "vacilação visual"18 como uma espécie de satori. Para Barthes, essa "vacilação" do olhar o lançaria em um campo aberto: "sou um selvagem, uma criança - ou um maníaco; mando embora todo saber, toda cultura, abstenho-me de herdar de um outro olhar"19. Essa dimensão enigmática do 
punctum é difícil de abordar, mas, se considerarmos os termos que Barthes utiliza para expressar essa "vacilação visual" diríamos que o abalo no sujeito do conhecimento ao produzir um "recuo dos signos" operaria "um vazio de fala" ${ }^{20}$. Um paradoxo em que o sujeito do saber, ao ser silenciado em seu discurso, poderia acionar na escrita a enunciação da "passagem de um vazio", para utilizarmos as expressões do autor.

O punctum de uma foto, sugere Barthes, "é esse acaso que, nela, me punge (mas também me mortifica, me fere)" "21. É o detalhe imprevisto de uma imagem, um pequeno ponto que ativa uma leitura intensificada pela necessidade de se aproximar daquilo que espontaneamente se apresenta: "Dessa vez, não sou eu que vou buscá-lo (como invisto com minha consciência soberana o campo do studium), é ele que parte em cena, como uma flecha, e vem me transpassar" 22 . Mais adiante, prossegue tentando registrar o modo como é ativada a leitura do punctum na imagem: "é ao mesmo tempo curta e ativa, encolhida como uma fera" ${ }^{23}$. Ou ainda, em outras palavras: "O efeito é seguro, mas não é situável, não encontra seu signo, seu nome; é certeiro e no entanto aterrissa em uma zona vaga de mim mesmo; é agudo e sufocado, grita em silêncio. Curiosa contradição: é um raio que flutua" ${ }^{24}$.

Barthes assinala que esses dois tipos de engajamento acionados na leitura de uma fotografia se manifestam no registro do que ele chama de uma "co-presença". Já em contraposição a essa concepção de imagem ativada em um campo de tensão (punctum e studium em ação concomitante), Barthes conceitua um outro tipo: a "fotografia unária". A saber, uma fotografia que "transforma enfaticamente a realidade, sem duplicá-la, sem fazê-la vacilar (a ênfase é uma força de coesão): nenhum duelo, nenhum indireto, nenhum distúrbio" ${ }^{25}$. Em uma sociedade produtora e disseminadora de imagens em profusão, as fotografias percebidas como "unárias" estão em permanente evidência: "Eu as folheio, não as rememoro; nelas, nunca um detalhe (em tal canto) vem cortar minha leitura: interesso-me por elas (como me interesso pelo mundo), não gosto delas" ${ }^{26}$.

É a ação do punctum na leitura de uma foto que provocaria, segundo Barthes, uma força de expansão para além do enquadramento da imagem: "O cinema (observou Bazin) não é um enquadramento, mas um esconderijo; o personagem que sai dela [a imagem] continua a viver: um "campo cego" duplica incessantemente a visão parcial" 27 . Ainda que o envolvimento através do studium quase sempre esteja incluído no processo de recepção de uma imagem e a parcela de participação de um e de outro não possa ser claramente distinguida, Barthes credita especialmente à ação do punctum essa expansão: "uma espécie de extracampo sutil, como se a imagem lançasse o desejo para além daquilo que ela dá a ver" ${ }^{28}$.
20. Idem. O Império dos Signos, 2007, p. 10.

21. Idem. A Câmara Clara: nota sobre a fotografia, 1984, p. 46.

22. Ibidem, p. 46.

23. Ibidem, p. 77.

24. Ibidem, p. 83.

25. Ibidem, p. 66.

26. Ibidem, p. 67.

27. Ibidem, p. 86.

28. Ibidem, p. 89. 
29. BARTHES, Roland. $A$ Câmara Clara: nota sobre a fotografia, 1984, p. 91.

\section{DIDI-HUBERMAN,} Georges. O que vemos, o que nos olha, 2010, p. 232.

31. BENJAMIN, Walter. "Questões introdutórias de crítica do conhecimento”, 1984, p. 50 .

32. Ibidem, p. 37.

33. BARTHES, Roland. $A$ Câmara Clara: nota sobre a fotografia, 1984, p. 95.

34. Ibidem, p. 104.
Em sua deambulação, Barthes interroga as imagens, tenta localizar o detalhe que lhe punge, o interesse cultural que esta ou aquela imagem provoca; elege um detalhe em uma foto e em seguida é absorvido por outro, se engana. No gesto da leitura das imagens deixa derivar seu interesse de um campo a outro: interroga aquilo que o detém, tenta precisar o movimento da imagem na consciência - pensamento, afeto - percebe a latência de imagens que retornam, fecha os olhos, se frustra:

Eu tinha de convir que meu prazer era um mediador imperfeito e que uma subjetividade reduzida a seu projeto hedonista não podia reconhecer o universal. Eu tinha de descer mais ainda em mim mesmo para encontrar a evidência da Fotografia. [...] Eu tinha de fazer a minha palinódia. ${ }^{29}$

\section{A fotografia do Jardim de Inverno}

E o limiar que se abre aí, entre o que Stephen Dedalus vê (o mar que se afasta) e o que o olha (a mãe que morre), esse limiar não é senão a abertura que ele carrega dentro de si, a 'ferida aberta de seu coração'so

Georges Didi-Huberman

A palinódia em um poema é uma retratação de algo já dito, um desdizer. Sendo assim, Barthes ao considerar que precisa fazer sua palinódia, ao final da primeira parte do livro, retoma o fôlego e recomeça. Em um movimento do pensar que faz lembrar a descrição de Benjamin ao se referir à contemplação do objeto (ou da verdade): "incansável, o pensamento começa sempre de novo, e volta sempre, minuciosamente, às próprias coisas" ${ }^{\prime 31}$. $\mathrm{Ou}$, como um escafandrista, querendo "descer mais fundo em si mesmo", em direção às águas escuras de "um centro silencioso, um bem erótico ou dilacerante, enterrado em mim mesmo" 32 . E é em nome do acaso que começa a segunda e última parte do livro "ora, numa noite de novembro, pouco depois da morte de minha mãe, organizei as fotos" ${ }^{33}$. Profundamente tocado pela morte da mãe, procura nas fotografias de família uma imagem que a ela corresponda, que faça jus à "verdade" de sua pessoa, tal como Barthes desejava reconhecer. Após passar diante de muitas imagens, reconhece em uma foto o que buscava: "por uma vez, a fotografia me dava um sentimento tão seguro quanto a lembrança, tal como a experimentou Proust" ${ }^{\prime 34}$. Diante da foto encontrada - a mãe com uns 5 anos, posando em um jardim de inverno - Barthes localiza o espanto que a fotografia lhe dava, tal como "diante dos olhos que viram o Imperador": 
Decidi então 'tirar' toda a fotografia (sua 'natureza') da única foto que com segurança existiu para mim, e tomá-la de certo modo como guia de minha última busca. Todas as fotografias do mundo formavam um labirinto. Eu sabia que no centro desse labirinto não encontraria nada além dessa única foto, cumprindo a palavra de Nietzsche: 'um homem labiríntico jamais busca a verdade, mas unicamente sua Ariadne. ${ }^{35}$

É a percepção da presença da mãe na foto que faz Barthes encontrar no referente da imagem "a ordem fundadora da fotografia"36: "a coisa necessariamente real que foi colocada diante da objetiva e sem a qual não haveria fotografia" 37 , aquilo que passa a nomear como o "isso-foi". No entanto, é especialmente o "isso-foi" como verdade da fotografia que Rouillé contesta. Para ele, Barthes estava como que cego ao não enxergar as fotos em si, em uma perspectiva que pudesse ser descolada do referente. Para Rouillé, o "isso- foi", ao destacar a marca do referente como elemento central em uma fotografia, acabou por colocá-la "sob uma tripla autoridade: a de um passado considerado como antigo presente, a da representação e a das substâncias" 38 .

A noção do "isso foi" (ente teórico irreal) encarcera a fotografia nos grilhões de uma problemática metafísica do ser e da existência, reduz a realidade a somente substância, nivelando-a em imagens 'sempre invisíveis' das coisas; e negligencia totalmente as formas fotográficas. [...] Saindo do universo abstrato das puras essências, chega-se ao mundo concreto e plural das práticas, das obras, das transições e das fusões. Porque, em si, no singular "a" fotografia não existe. $^{39}$

Nesse sentido, o que Rouillé defende é a autonomia da fotografia perante o seu referente. Mas, para ele, o Barthes teórico é desmentido pelo Barthes espectador da imagem: "ao procurar a mãe recentemente desaparecida que havia conhecido, ele se confronta com um híbrido, fabuloso e incomunicável, de menina e de velha senhora, que jamais pode ser vista nem vivida"40. Sendo assim, é uma foto da mãe de Barthes menina, muito antes do seu nascimento, que o faz remontar no tempo e restitui sua presença, experiência que aciona em Barthes o cruzamento de uma temporalidade complexa. É uma imagem intempestiva, cuja "atualização" no ato da recepção a inscreve em um circuito em que diferentes temporalidades interagem em uma imagem. Ainda a esse respeito, escreve Rouillé:

Perceber um objeto atual presente significa, portanto, associar-lhe uma imagem virtual que o reflita e o envolva, e inseri-lo nos circuitos que o absorvem entre percepção e lembrança, real e imaginário, físico e mental. A percepção
35. Ibidem, p. 119.

36. Ibidem, p. 115.

37. Ibidem, p. 115.

38. ROUILLÉ, André. $A$

Fotografia - entre documento e arte contemporânea, 2009, p. 71.

39. Ibidem, p. 18.

40. Ibidem, p. 222. 
41. Ibidem, p. 213.

42. BARTHES, Roland. $A$ Câmara Clara: nota sobre a fotografia, 1984, p. 121.

43. Ibidem, p. 141. de uma fotografia atual, presente aqui e agora, será acompanhada da criação de uma imagem virtual, espécie de duplo ou reflexo, com a qual ela forma uma unidade: uma imagem-cristal, em que se permutam o atual e o virtual, o real e o imaginário, o presente e o passado. ${ }^{41}$

Barthes, ao se deparar com a "fotografia do jardim de inverno" que o toca "como os raios retardados de uma estrela" empreende uma "aventura" pelos desvãos da memória e percebe uma outra vertigem encoberta na imagem: "sei agora que existe um outro punctum (um outro estigma) que não o 'detalhe'. Esse novo punctum, que não é mais de forma, mas de intensidade, é o Tempo"43.

\section{Referências}

BARTHES, Roland. Aula. São Paulo: Editora Cultrix, 1996. - A Câmara Clara: nota sobre a fotografia. Rio de Janeiro: Editora Nova Fronteira, 1984.

. O Império dos Signos. São Paulo: WMF Martins Fontes, 2007.

BENJAMIN, Walter. "Questões introdutórias de crítica do conhecimento". In: . Origem do Drama Barroco Alemão. São Paulo: Brasiliense, 1984.

DIDI-HUBERMAN, Georges. O que vemos, o que nos olha, São Paulo: Editora 34, 2010.

ROUILLÉ, André. A Fotografia - entre documento e arte contemporânea. São Paulo: Senac, 2009. 